\title{
Effect of Hospital-Based Providers Continuous Support on Progress of Active Phase of Labor
}

\author{
Gehan Ebrahim Ghonemy ${ }^{1 *}$, Entesar Fatouh Abd El Moneim ${ }^{2}$, Zeinab Ahmed Abdelsalam ${ }^{3}$ \\ ${ }^{1}$ Associate Professor of Maternal and Newborn Health, Nursing, Faculty of Nursing Cairo University \\ ${ }^{2}$ Associate Professor of Maternal and Newborn Health, Nursing, Faculty of Nursing Helwan University \\ ${ }^{3}$ Lecturer of Psychiatric Mental Health Nursing, Faculty of Nursing, Cairo University
}

Received: March 12, 2017; Accepted: : April 8, 2017; Published: April 14, 2017

*Corresponding author: Dr. Gehan Ebrahim Ghonemy, Associate professor of maternal and newborn health Nursing, Cairo University. E-mail: gghonemy@ hotmail.com

\begin{abstract}
The labor and delivery experience is one of the most significant events in a woman and spouse life, and can have strong physical, emotional, and psychological effects.

Aim of the study: To evaluate the effect of continuous support provided by nurses during labor on the duration of the active phase of labor.

Method: A quasi- experimental design was adopted, using Apurposive Sample of 200 women was randomly divided into control group $(\mathrm{n}=100)$ who had not received support on childbirth. In the intervention group $(n=100)$ continuous support during labor was provided. Data collected using an interview sheet, a partograph (labor progress record), and visual analogue scale to assess severity of pain.
\end{abstract}

Results: The two groups did not differ by age, employment, educational level, residence. Mean duration of the active phase of labor ( $4.5 \pm 0.53$ vs $5.39 \pm 0.89 \mathrm{hrs}, \mathrm{p}<0.000$ ) were significantly lower in the intervention group compared with the control one.

Conclusion and recommendation: Continuous support provided by nurses during labor may reduce the duration of labor; this model of support should be available to all women during labor

Keywords: Continuous Supportive Care; Duration of Labor.

\section{Introduction}

The labor and delivery experience is one of the most significant events in a woman and spouse life, and can have strong physical, emotional, and psychological effects. As well as, labor support is done when there is someone with you during childbirth whose role is to help women stay comfortable, move through her birthing process, remind you that what's happening is normal and healthy and give information about your care.

To assess who might best provide labor support, one must first understand exactly what labor support is and how it works. The primary theorized mechanism of action involves the cycle of fear-tension-pain observed by Dr. Grantley Dick-Read, an early proponent of childbirth education and labor support. The theory states that pain and anxiety during labor lead to an endogenous release of catecholamines, which lower uterine contractility and decrease placental blood flow. Less anxiety means decreased catecholamines, improved uterine contractility and efficiency, and a reduced risk of prolonged labor or fetal distress. Women with continuous labor support feel empowered and in control and, therefore, experience less anxiety than their non-supported counterparts [9]. Using "labor support specialist" or "doula" may also help in move around during labor. She will usually support your spouse or partner and others in the room as well [7]. Last century, birth in the United States (US) moved from a woman-supported experience in the home to a highly medicalized event in the hospital. Although immediate pregnancy outcomes for mother and baby have improved, rates of medical intervention and operative delivery have increased, and problems such as failure to breastfeed, difficulties coping as a mother and high rates of postpartum depression remain prevalent as reported by Patricia Rosen [14]. Research suggests that continuous labor support may mitigate some of these adverse outcomes. The components of labor support that women report finding helpful or emotional support (continuous presence, reassurance, encouragement, and praise); physical support (comfort measures aimed at decreasing hunger, thirst, or pain); information and advice about what is happening and how to cope; advocacy (respecting her decisions and helping to communicate those to the health care team); and caregiver support of the partner/ husband. All of these components imply a human presence that accepts a woman's behavior, attitudes, and individual preferences [5].

Research says that having support from a doula or other labor support specialist who is present solely to provide continuous support has the most benefits to alleviate the labor pain. Others who may be important sources of support either partner, clinical caregivers and friends or family members [8]. Continuous support in labour is associated with shorter labor and reduced requirement for analgesia. Although, trained labor support specialist or doula and other common names include labor companion, labor support professional, labor support specialist, labor assistant and birth assistant. This type of labor support specialist offers the greatest benefits for your health and safety during labor and birth [11]. As well, spouse or partner can also act, while many partners are worried about accompanying a 
woman during labor, most find that providing help and comfort in labor is very rewarding and that being present at the birth of their child is one of life's highlights. As the woman needs to tolerate with her labor progress and need to come to clinical caregiver: In most cases, this would be a nurse, midwife or doctor, are commonly acts. While, relative or friend: can be chosen from someone in a certain social network with whom you (and your partner, if you have one) feel comfortable sharing this important and intimate time. She or he should be a warm, relaxed and calm person who views labor and birth as healthy, normal events in a woman's life [3]. Although, the progress of labor causing a pain which is unique to each women. How she perceives or interprets that pain, and the factors influencing this pain as physiological, psychological, emotional, social and environmental factors [17]. Other physical factors that affect pain intensity include fatigue, the interval and duration of concentrations, fetal size and position, rapidity of fetal descent and maternal position [2]. Hospital-based providers may have difficulty giving a women the best possible labor support for several reasons: as responsibility to others, and care that doesn't involve support and Nurses work in shifts, so nurses might come and go throughout your labor. Doctors and midwives often rotate being "on call," which means a new person may attend your birth. It is unlikely that you will have met the nurses. For these reasons, clinical caregivers in hospitals are rarely able to offer the direct, continuous personalized labor support that has been shown to be so beneficial for laboring women. These factors are less likely to be a problem at out-of-hospital ("freestanding") birth centers. They would rarely have an impact on home birth care [7]. Many laboring women suffering during their first stage of labor under routine care, either from medical or nursing team, which had an adverse effect on the progress of labor and maternal physical and psychological wellbeing. In Egypt, there are routine care providing to the women in labor at the governmental hospital, where the proper support is not theirs. But in privet one support system with a new modality was existed, because of its cost effect. So the current study is focusing on evaluating the effect of using continuous support provided by nurses during labor on the duration of the active phase of labor.

\section{Methodology}

A quasi-experimental design was adopted to achieve the aim of the study, which is "Evaluate the effect of continuous support provided by nurses during labor on the duration of the active phase of labor." and this aim prepared to test the research hypothesis which is ": laboring women who receive continued support during their active phase of labor will experience less pain scores and shorter duration than those who received routine intervention ". Setting: The study was carried out in one of the governmental maternity hospital in Cairo| Egypt, while a lot of female use to deliver their with no cost effect. Sample: An Apurposive Sample, total of 200 laboring women was selected with inclusion criteria of: any number of para, vertex presentation, and single full term baby, in active phase of labor, did not have any medical or obstetrical problems. A sample was randomly assigned into two groups (100) each, one of them received a continues support (study group), while the other one (control group) had a routine nursing care. Ethical considerations: The researchers obtained an official approval from the director of the hospital and from the eligible laboring women who accepted to participate in the study.

\section{Procedure}

All laboring women who invited to this study were informed about the purpose of the study and its importance. The researcher emphasized that participation in the study was voluntary, and anonymity with confidentiality were assured. Each laboring was shared in the study was signed a consent form, and informed her that she has the right to withdraw from the study at any time she need without any restriction. World Health Organization (WHO) partograph (labor progress record) and instruction interview sheet were used to assess sociodemographic data and obstetrical profile as well as current pregnancy profile [16]. Also, a Visual Analog Scale (VAS) was adopted, which consists of ten points on one line with numbers and facial picture (scoring from zero, which indicates no pain and the top score is ten with worst pain). During the implementation phase, which is carried out through a psychological and physical support, through continuing health teaching, providing to each procedure carried out for each laboring women to clarify the purpose and effect of each procedure carried out, as well as use breathing exercises with sacral massage during each contraction with relaxation after to distract her attention to labor pain as well as increase her supplementation of oxygen inhalation to alleviate the pain. Continuous discussions with the women regarding how her laboring process going on ,and how her baby reacts with frequent sharing mothers listening of their fetal heart sound , massage and handholding to convey to the woman emotional support, through the use of positive reassurance, encouragement and honest praise. Also, the researchers suggested ways to improve labor progress or ease discomfort, explain what is happening or interpret what hospital personnel have said, communicate the women needs to hospital staff and support decisions have made. This procedure was carried out during the active phase of labor only (cervix more than $3 \mathrm{~cm}$ until it becomes $10 \mathrm{~cm}$ ). Labor progress and pain scale was used to monitor the progress of labor and the pain changes each half an hour for six hours each.

Statistical data analysis: the collected data was tabulated in number and percentages for categorical variables, and mean and standard deviations for numeric variables. Repeated measures analysis was used to find the differences among the measures of pain. For difference between categorical variables Chi-square test was used (X2). The level of significance in the current study was $(\mathrm{P} \leq 0.0)$. There is a significant variation between the groups, using t-test compares means. While the ANOVA compares variances between study samples. Analysis of Variance, or ANOVA for short, is a statistical test that looks for significant differences between means. One way ANOVA gave a single number (the F-statistic) and one p-value to help in support or reject the hypothesis. Even though test each at a 95\% level of confidence, while P level significant at $\leq 0.05$. 


\section{Results:}

Results of the study reported in different parts in order to convey the aim of the study, which is "Evaluate the effect of continuous support provided by nurses during labor on the duration of the active phase of labor."

The first part related to socio-demography and obstetric profile. Results reported that the subjects mean age was $(26.37$ \pm 4.73 ) for study group and $(26.37 \pm 4.27)$ for the control group with average of 25 yrs old. No significant statistical differences was found between both group regarding their age $(\mathrm{t}=-.031, \mathrm{p}=$ 0.976). As well as, the level of education, occupation and residence did not show any significant statistical differences found between both group (X2 = 3.349, $\mathrm{p}=0.501 ; \mathrm{X} 2=0.992, \mathrm{p}=0.319 ; \mathrm{X} 2$ $=0.088, p=0.767$ respectively) In relation to their obstetric profile , the results reported that $54 \%$ of the study group was multiparas compared to $61 \%$ of the control one, also , $46 \%$ and $39 \%$ of the study and control group respectively was primipara , with no statistical significant differences between both groups $(\mathrm{X} 2=1.003, \mathrm{p}=0.317)$. Gestational age (38.65 \pm 0.91$)$ among the study group, compared to $(39.07 \pm 0.83)$ among the control one.

In relation to finding that relay on the effect of continuous supportive care on labor pain intensity and progress of labor. The results revealed that the mean of labor score among the study group was $(4.16 \pm 0.288)$ after 30 min from starting health teaching with breathing exercises and sacral massage, and it was $4.28 \pm 0.347$ among the control group, which revealed a significant difference between both groups mean labor scores which monitored every half an hour up to the time of delivery( $\mathrm{F}=$ 11.77, $\mathrm{p}=0.001$ ), as listed in (Table 2).

\begin{tabular}{|c|c|c|c|c|c|c|}
\hline \multirow[t]{2}{*}{ Personal data } & \multicolumn{2}{|c|}{ Study group } & \multicolumn{2}{|c|}{ Control group } & \multirow[t]{2}{*}{ t-test } & \multirow[t]{2}{*}{$\mathrm{p}$} \\
\hline & Mean & $\pm \mathrm{SD}$ & mean & $\pm \mathrm{SD}$ & & \\
\hline Age & 26.37 & 4.73 & 26.37 & 4.27 & -0.031 & 0.976 \\
\hline $\begin{array}{c}\text { Level of } \\
\text { education }\end{array}$ & No. & $\%$ & No. & $\%$ & $\mathrm{X}^{2}$ & $\mathrm{p}$ \\
\hline Read and write & 14 & 14 & 19 & 19 & \multirow[t]{5}{*}{3.349} & \multirow[t]{5}{*}{0.501} \\
\hline Primary & 38 & 38 & 27 & 27 & & \\
\hline Preparatory & 32 & 32 & 39 & 39 & & \\
\hline Secondary & 13 & 13 & 12 & 12 & & \\
\hline University & 3 & 3 & 3 & 3 & & \\
\hline \multicolumn{7}{|c|}{ Occupation } \\
\hline House wife & 52 & 52 & 59 & 59 & \multirow[t]{2}{*}{0.992} & \multirow[t]{2}{*}{0.319} \\
\hline Working & 48 & 48 & 41 & 41 & & \\
\hline \multicolumn{7}{|c|}{ Residence } \\
\hline Urban & 34 & 34 & 36 & 36 & \multirow[t]{2}{*}{0.088} & \multirow[t]{2}{*}{0.767} \\
\hline Rural & 66 & 66 & 64 & 64 & & \\
\hline
\end{tabular}

Table 2:Distribution of the subjects according to their mean labor pain scores among the study and control groups

\begin{tabular}{|c|c|c|c|c|}
\hline Time of & Study group & Control group & $\mathrm{F}$ & $\mathrm{p}$ \\
\hline assessment & $\mathrm{M} \pm \mathrm{SD}$ & $\mathrm{M} \pm \mathrm{SD}$ & \multirow{13}{*}{11.77} & \multirow{13}{*}{$\begin{array}{c}0.001 \\
\text { Sign. }\end{array}$} \\
\hline On admission & $3.84 \pm 0.026$ & $3.79 \pm 0.34$ & & \\
\hline After half hour & $4.16 \pm 0.288$ & $4.28 \pm 0.347$ & & \\
\hline After one hour & $4.66 \pm 0.288$ & $4.90 \pm 0.315$ & & \\
\hline After $1.30 \mathrm{hr}$ & $4.83 \pm 0.288$ & $5.31 \pm 0.375$ & & \\
\hline After $2 \mathrm{hrs}$ & $5.30 \pm 0.264$ & $5.87 \pm 0.393$ & & \\
\hline After $2.30 \mathrm{hrs}$ & $5.53 \pm 0.50$ & $6.25 \pm 0.424$ & & \\
\hline After 3hrs & $5.83 \pm 0.763$ & $6.80 \pm 0.452$ & & \\
\hline After3.30hrs & $6.06 \pm 0.513$ & $7.15 \pm 0.471$ & & \\
\hline After $4 \mathrm{hrs}$ & $6.46 \pm 0.83$ & $7.67 \pm 0.444$ & & \\
\hline After $4.30 \mathrm{hrs}$ & $6.66 \pm 0.57$ & $7.93 \pm 0.483$ & & \\
\hline After 5 hrs & $7.16 \pm 0.57$ & $8.50 \pm 0.49$ & & \\
\hline After $5.30 \mathrm{hrs}$ & $8.00 \pm 0.866$ & $8.88 \pm 0.614$ & & \\
\hline
\end{tabular}

Significant difference calculate at $95 \%$ level of confidence $\& P$. $\leq 0.05$

Although the pain scores increased as the labor progressed, the maximum effect of support was reported after 2.30 hours from admission with a mean of $(5.53 \pm 0.50)$ and $(6.25$ \pm 0.42 ) to the study and control group respectively. Although the pain intensity regain to rise again against the level of admission after the lap of three hours as the progress of labor enhanced. As well repeated measures by using ANOVA, which determine the mean visual analogue score show statistically significant differences between time points $(\mathrm{F}=332.31, \mathrm{p}=0.05)$ as the study group was reported less level of pain score than the control one.

In relation to the pattern of labor progress, there was a statistical significant differences was reported between the study and control group in relation to that progress. The progress was monitored using the frequency and duration of the uterine contraction throughout the active phase of labor as well as the progress in the station, effacement and cervical dilatation against the admission date.

Regarding a uterine contraction frequencies and duration through six hours from admission time, results indicated an increase numbers of contractions from 3.05 to 4.00 per ten minute contraction among the study group compared to 3.03 to 4.00 among the control one. While the duration of contraction was less in the study group $(53.9,39.35,43.22,48.49 \& 55.65$ second respectively) compared to(34.11, 37.97,40.24, 44.83, 52.18 \& 61.72 second respectively) among the control group. A significant differences also was found in a uterine contraction and duration among supported and control groups as reported by the results $(\mathrm{F}=5.51 ; \mathrm{P}=0.021$ and $\mathrm{F}=5.2 ; \mathrm{P}=0.025$ respectively) (Table 3). This reflected the role of the supported intervention on the study group. 
Table 3: Mean changes of labor progress among the study and control group during the active phase in relation to uterine contractions in progress.

\begin{tabular}{|c|c|c|c|c|c|c|c|c|}
\hline \multirow[t]{3}{*}{ Time of assessment } & \multicolumn{4}{|c|}{ Uterine contractions frequencies per $10 \mathrm{~min}$} & \multicolumn{4}{|c|}{ Uterine contractions duration by second } \\
\hline & Study group & Control group & F. & $\mathrm{p}$ & Study group & $\begin{array}{l}\text { Control } \\
\text { group }\end{array}$ & $\mathrm{F}$ & $\mathrm{p}$ \\
\hline & $\mathrm{M} \pm \mathrm{SD}$ & $\mathrm{M} \pm \mathrm{SD}$ & \multirow{7}{*}{5.51} & \multirow{7}{*}{$\begin{array}{l}0.021 \\
\text { *Sign. }\end{array}$} & $\mathrm{M} \pm \mathrm{SD}$ & $\mathrm{M} \pm \mathrm{SD}$ & \multirow{7}{*}{5.2} & \multirow{7}{*}{$\begin{array}{l}0.025 \\
* \text { Sign }\end{array}$} \\
\hline $1^{\text {st }}$ hour from admission & $3.05 \pm 0.21$ & $3.03 \pm 0.17$ & & & $35.92 \pm 1.23$ & $34.11 \pm 2.80$ & & \\
\hline $2^{\text {nd }}$ hour $(\mathrm{AA})$ & $3.18 \pm 0.39$ & $3.57 \pm 0.50$ & & & $36.45 \pm 1.89$ & $37.97 \pm 1.01$ & & \\
\hline $3^{\text {rd }}$ hour(AA) & $3.97 \pm 0.18$ & $4.00 \pm 0.00$ & & & $39.35 \pm 2.13$ & $40.24 \pm 1.51$ & & \\
\hline $4^{\text {th }}$ hour(AA) & $4.00 \pm 0.00$ & $4.00 \pm 0.00$ & & & $43.22 \pm 3.65$ & $44.83 \pm 1.84$ & & \\
\hline $5^{\text {th }}$ hour(AD) & $4.05 \pm 0.229$ & $4.13 \pm 0.34$ & & & $48.49 \pm 1.62$ & $52.18 \pm 3.32$ & & \\
\hline $6^{\text {th }}$ hour(AD) & $4.00 \pm 0.29$ & $4.00 \pm 0.00$ & & & $55.65 \pm 1.56$ & $61.72 \pm 3.01$ & & \\
\hline \multicolumn{9}{|c|}{ NB : (AA) means during active acceleration phase, and (AD) means active deceleration phase } \\
\hline
\end{tabular}

Progress of cervical dilatation was observed from the first hour after admission till six hours after among study group \& control one. while the study group show rapid progress than the study group $(4.00,5.07,6.10 .7 .36,8.50,9.84$ on the study group respectively compared to $4.00,4.96,5.73,7.47,8.48$ respectively the control group. ). Significant differences was found in a cervical condition among both groups $(\mathrm{F}=71.25$ and $\mathrm{P}=0.000)$ for the progress of effacement and $(F=119.91$ and $P=0.000)$
While the duration of active decelerations phase did not report any significant differences between the study \& control group $(M \pm S D$ was $1.24 \pm 0.36$ and $1.26 \pm 0.41$ respectively) with nosignificant differences as P. value (0.608). Over all the total duration of first stage of labor show significant differences regarding $(\mathrm{P} .=0.000)$.

Table 4: Mean changes of labor progress among the study and control group during the active phase in relation to cervical condition.

\begin{tabular}{|c|c|c|c|c|c|c|c|c|}
\hline \multirow{3}{*}{$\begin{array}{l}\text { Time of assessment } \\
\text { from admission }\end{array}$} & \multicolumn{4}{|c|}{ Cervical dilatation by $\mathrm{cm}$} & \multicolumn{4}{|c|}{ Cervical effacement by \% } \\
\hline & $\begin{array}{l}\text { Study } \\
\text { group }\end{array}$ & $\begin{array}{l}\text { Control } \\
\text { group }\end{array}$ & F. & P. & Study group & $\begin{array}{l}\text { Control } \\
\text { group }\end{array}$ & $\mathrm{F}$. & P. \\
\hline & $\mathrm{M} \pm \mathrm{SD}$ & $\mathrm{M} \pm \mathrm{SD}$ & \multirow{7}{*}{119.91} & \multirow{7}{*}{$\begin{array}{l}.000 \\
\text { Sig }\end{array}$} & $\mathrm{M} \pm \mathrm{SD}$ & $\mathrm{M} \pm \mathrm{SD}$ & \multirow{7}{*}{71.25} & \multirow{7}{*}{$\begin{array}{l}.000 \\
\text { Sign }\end{array}$} \\
\hline $1^{\text {sthour }}$ & $4.00 \pm .00$ & $4.00 \pm .00$ & & & $55.35 \pm 5.01$ & $52.20 \pm 4.16$ & & \\
\hline $2^{\text {nd }}$ hour & $5.07 \pm .18$ & $4.96 \pm .30$ & & & $65.25 \pm 5.01$ & $60.50 \pm 5.75$ & & \\
\hline $3^{\text {rd }}$ hour & $6.10 \pm .37$ & $5.73 \pm .52$ & & & $75.25 \pm 5.21$ & $67.80 \pm 7.18$ & & \\
\hline $4^{\text {th }}$ hour & $7.36 \pm .44$ & $6.53 \pm .51$ & & & $85.25 \pm 5.21$ & $76.60 \pm 7.41$ & & \\
\hline $5^{\text {th }}$ hour & $8.50 \pm .36$ & $7.47 \pm .51$ & & & \multirow[t]{2}{*}{$95.25 \pm 5.21$} & \multirow[t]{2}{*}{$86.10 \pm 8.02$} & & \\
\hline $6^{\text {th }}$ hour & $9.84 \pm .36$ & $8.48 \pm .59$ & & & & & & \\
\hline
\end{tabular}

for the dilatation. This changes due to rapid progress of study group than the control one (Table 4).

In relation to station of the presenting part, the result indicate a significant statistical changes between both group using ANOVA test $(\mathrm{F}=12.38$ and $\mathrm{P}=0.001)$, as the cases in the study group show more rapid progress in their fetal descent rather than the control one (Table 5).

Finally, (Table 6) conclude how the labor duration was longer at control group rather than the study one, as the mean active phase at study group was 4.5 hours compared to the control group which was 5.39 hours $(\mathrm{t}=-9.103$ and $\mathrm{p}=0.000)$.

\begin{tabular}{|c|c|c|c|c|}
\hline \multirow[t]{3}{*}{ Station level at } & \multicolumn{4}{|c|}{ Station progress } \\
\hline & Study group & Control group & $\mathrm{F}$ & $\mathrm{p}$ \\
\hline & $\mathrm{M} \pm \mathrm{SD}$ & $\mathrm{M} \pm \mathrm{SD}$ & \multirow{7}{*}{12.38} & \multirow{7}{*}{$\begin{array}{l}0.001 \\
* * \text { Sign. }\end{array}$} \\
\hline-2 (on admission) & $1.83 \pm 0.38$ & $1.65 \pm 0.65$ & & \\
\hline-1 & $1.65 \pm 0.48$ & $1.21 \pm 0.62$ & & \\
\hline 0 & $0.67 \pm 0.47$ & $0.67 \pm 0.47$ & & \\
\hline 1 & $0.28 \pm 0.50$ & $0.20 \pm 0.40$ & & \\
\hline 2 & $1.05 \pm 0.21$ & $1.0 \pm 0.00$ & & \\
\hline 3 & $1.97 \pm 0.15$ & $1.95 \pm 0.21$ & & \\
\hline
\end{tabular}

*Significant difference calculate at $95 \%$ level of confidence \& P. $\leq 0.05^{* *}$ highly significant 


\begin{tabular}{|l|l|l|l|l|}
\hline $\begin{array}{l}\text { Table(6):The effect of support on labor duration among the study } \\
\text { and control group. }\end{array}$ \\
\hline $\begin{array}{l}\text { Labor duration by } \\
\text { hours }\end{array}$ & $\begin{array}{l}\mid c \text { Station progress } \\
\text { group d y }\end{array}$ & $\begin{array}{l}\text { C o n t r o l } \\
\text { group }\end{array}$ & T test & p \\
\cline { 2 - 5 } & M \pm SD & M \pm SD & & \\
\hline $\begin{array}{l}\text { Active } \\
\text { acceleration } \\
\text { phase }\end{array}$ & $3.21 \pm 0.38$ & $4.13 \pm 0.78$ & -10.593 & $0.000^{* *}$ \\
\hline $\begin{array}{l}\text { Active } \\
\text { deceleration } \\
\text { phase }\end{array}$ & $1.24 \pm 0.36$ & $1.26 \pm 0.41$ & -0.514 & 0.608 \\
\hline totalactive phase & $4.5 \pm 0.53$ & $5.39 \pm 0.89$ & -9.103 & $0.000^{* *}$ \\
\hline *significant $<0.05 * *$ highly significant & & \\
\hline
\end{tabular}

\section{Discussion:}

Physical and psychological support in active labor by an experienced female companion is associated with significantly less need for analgesia, forceps or vacuum extraction, and cesarean births, fewer low Apgar scores, shorter duration of labor, decreased oxytocin augmentation, and an increased sense of personal control. In the long term, support is associated with lower rates of postpartum depression, failed breastfeeding, difficult mothering, and negative perceptions of the birth experience [15]. According to a 1999 metanalysis, positive outcomes are limited to studies in which continuous labor support is compared with none at all [5]. The current study will discuss its results on the frame of suggested hypothesis which is "laboring women who receive continued support during their active phase of labor will experience less pain score and shorter duration than those who received routine intervention ". So discussion will carry out on the frame of two parts, the first one will discuss the pain severity and second part will relay on the progress of labor.

In relation to the first part which explain the labor pain, finding of this study supported the first half of the research hypothesis which reported that" laboring women who receive continued support during their active phase of labor will experience less pain score". Results related to pain score reported no significant differences between both group pain score on admission (3.84 \pm 0.26$)$ among study group and (3.79 \pm 0.34$)$ among control one with $(p=0.299)$. Compared to the progress of labour, the pain mean score recorded among both group each half an hour repeated its measuring by using ANOVA test, reported marked significant differences of the visual analogue pain scores among both groups as $(\mathrm{F}=11.77$ and $\mathrm{p}=0.001$, Table 2). This finding is supported by who reported that some studies have been done on pain relief and massage [10]. One of the studies involved massage found that the woman's anxiety and pain was reduced and her mood improved. Another concluded that massage was a cost-effective option that could be implemented by midwives. Also, a Cochrane systematic review found that the women who receive midwife continuity of support are less likely to have pharmacological pain relief in labor [1].
Women perceived a reduction in their pain and anxiety levels, and found with partner involvement, they had a more positive birth experience. Yet another concluded that women who were massaged during labour were less anxious, experienced less pain, had shorter labors and experienced less postnatal depression, opposed to the control group of women who did not receive massage. Also, a survey carried out by Nikula; Laukkala; and Pölkki, reported that the mothers perceived emotional assistance to be most important [12]. From the list of midwives' labor support behaviors provided in the survey, the following were considered most helpful: giving praise, treating on an individual basis, and answering questions truthfully and understandably. Clinical implications: emotional, tangible, and informational labor support enhanced the mothers' birth experiences. Labor support should be provided when caring for every mother during childbirth. An evidence-based model of labor support should be used for nursing and midwifery education and clinical practice. As well as, Hamidzadeh, et al. conducting a single, blind, randomized clinical trial on 100 women at the beginning of active phase of labour and the results reported an effective progress of the group with acupressure rather than group with touching support only [4]. Also they recommended to enhance the role of nurses in Education given to the laboring women and most properly assess the level of laboring women pain.

Second part which related to progress of labor, the results of the current study reported better labor progress between the study and control group over time in cervical dilatation. The results revealed short active phase of the first stage of labor was found among women who receive continuous support than the control group (means of $4.5 \pm 0.53$ and $5.39 \pm$ 0.89 hours respectively). This progress of labor explained how this continuous support plays a crucial role in decreasing the women stress and playing a role in achieving better coping with the pain produced from the contraction , and this tolerance help the women to accommodate her labor progress and make it in a short period than the control group. This finding consistent with another study on continuous support provided by midwives during labor and reducing the duration of labor and the number of cesarean deliveries; and recommend to apply this model of support should be available to all women [8].

Also Hodnett, et al. supported same idea and reported that Women who received continuous labour support were more likely to give birth 'spontaneously', i.e. give birth with neither caesarean nor vacuum nor forceps [6]. In addition, women were less likely to use pain medications, were more likely to be satisfied, and had slightly shorter labors. No adverse effects were identified. And the authors conclude that all women should have continuous support during labour. On the same track, Reda , reported in her study that continuous intrapartum support were less likely to report dissatisfaction with their childbirth experiences, as well as its important to overcome the use of pain relive during labor, which will indirectly enhance the progress of labour \& maintain the newborn health condition [13]. 


\section{Conclusion\& Recommendations}

The results of the study concluded marked decrease of the labor pain among the study group compared with the control one. As well as the progress of active phase of labor was markedly shown significantly differ among the supported group compared with the control one. The study recommended a great need to raise the awareness and increase the knowledge of maternity nurses, midwife, \& physician to provide effective continuous psychological and physical support for women during labor.

\section{References}

1. Association of Women's Health Obestetric \& Neonatal Nurses, AWHONN. Role of the registered nurse in the care of the pregnant woman receiving analgesia \& anesthesia by catheter technique: clinical position statement. J Obst. Gyne Neonatal Nurse. 2012;41(3):455-457. doi: 10.1111/j.1552-6909.2012.01364

2. Blackburn S. Maternal, Fetal and neonatal physiology: A clinical perspective.(4th ed.) St Louis: Saunders; 2013.

3. Escott D, Slade P, Spiby H. Preparation for pain management during childbirth: the psychological aspects of coping strategy development in antenatal education. Clin Psychol Rev. 2009;29(7):617-622. doi: 10.1016/j.cpr.2009.07.002

4. Hamidzadeh A, Shahpourian F, Orak RJ, Montazeri AS, Khosravi A Effects of LI4 acupressure on labor pain in the first stage of labor. J Midwifery Womens Health. 2012;57(2):133-138. doi: 10.1111/ j.1542-2011.2011.00138

5. Hodnett ED. Pain and women's satisfaction with the experience of childbirth: A systematic review. Am J Obstet Gynecol. 2002;186(5 Suppl Nature):S160-172

6. Hodnett ED, Gates S, Hofmeyr G, Sakala C. Continuous support for women during childbirth. Cochrane Database of systematic Review. 2013;(7): CD003766. doi: 10.1002/14651858.CD003766
7. International Journal of Gynecology and Obstetrics. 2010;109(3):198200 JAMA . Available at: https://www.bellybelly.com.au/birth/natuapain-relief-for-labour/

8. Kashanian M, Javadi F, Haghighi M. Effect of continuous support during labor on duration of labor and rate of cesarean delivery. Elsevier B.V. 2017.

9. Kayne MA, Greulich MB, Albers LL. Doulas: an alternative yet complementary addition to care during childbirth. Clin Obstet Gynecol. 2001;44(4):692-703.

10. Kelly W. Natural Pain Relief Options for Labour, American Medical Association. 2016

11. Manizheh P, Leila P. Perceived environmental stressors and pain perception during labor among primiparous and multiparous women. J Reprod Infertil. 2009;10(3):217-223.

12. Nikula P; Laukkala H; Pölkki T. Mothers' Perceptions of Labor Support. American Journal of Maternal Child Nursing. 2015;40(6):373-380. doi: 10.1097/NMC.0000000000000190

13. Reda D. Effect of ice cold massage on the relief of labour pain among laboring women, unpublished thesis. 2014.

14. Rosen P. Supporting Women in Labor: Analysis of Different Types of Caregivers. J Midwifery Womens Health. 2004;49(1):24-31. doi: 10.1016/j.jmwh.2003.10.013

15. Walker R, Turnbull D, Wilkinson C. Strategies to address global cesarean section rates: a review of the evidence. Birth. 2002;29(1):2839.

16. WHO. World Health Organization Partograph in Management of labor. 2000;343:1399-1404.

17.Zwelling E, Johnson K, Allen J. How to implement complementary therapies for laboring women. MCN Am J Matern Child Nurs. 2006;31(6):364-370. 